\title{
Counterbalance Device
}

National Cancer Institute

\section{Source}

National Cancer Institute. Counterbalance Device. NCI Thesaurus. Code C50352.

A weight designed to counteract the effects of another weight. 